\title{
Completion pneumonectomy and auto-transplantation for bronchopleural fistula
}

Masatsugu Hamaji, MD, PhD, Toyofumi Fengshi Chen-Yoshikawa, MD, PhD, and Hiroshi Date, MD, PhD, Kyoto, Japan

From the Department of Thoracic Surgery, Kyoto University Hospital, Kyoto, Japan.

Disclosures: Authors have nothing to disclose with regard to commercial support.

Received for publication Feb 23, 2019; revisions received March 27, 2019; accepted for publication April 16,

2019; available ahead of print June 14, 2019.

Address for reprints: Hiroshi Date, MD, PhD, Department of Thoracic Surgery, Kyoto University Hospital, 54

Kawaharacho, Shogoin, Sakyo-ku, Kyoto, 606-8507, Japan (E-mail: hdate@kuhp.kyoto-u.ac.jp).

J Thorac Cardiovasc Surg 2019;158:e121-3

$0022-5223 / \$ 36.00$

Copyright (C) 2019 Published by Elsevier Inc. on behalf of The American Association for Thoracic Surgery

https://doi.org/10.1016/j.jtcvs.2019.04.093

- Video clip is available online.

There is a dearth of data regarding the management of a bronchial anastomotic stenosis after a sleeve lobectomy. ${ }^{1}$ Endoscopic management seems to be effective and preferred, whereas a refractory bronchial stenosis may require completion pneumonectomy, which is associated with high operative mortality. ${ }^{1}$ We report a patient who underwent completion pneumonectomy and autotransplantation for bronchopleural fistula.

\section{CASE REPORT}

A 55-year-old man was diagnosed with squamous cell carcinoma originating in the right upper lobe, which extended to the orifice of the right upper lobe bronchus (Figure 1, A). We performed a fourth intercostal thoracotomy and a right upper sleeve lobectomy, requiring a plication of the carina (Video 1). The bronchial anastomosis was performed with 4-0 polydioxanone continuous and interrupted stitches. Hilar release was performed, and the intercostal muscle flap was sutured to the anastomosis. The final pathology was T2N1M0.

Two months postoperatively, the anastomosis was almost occluded with benign granulation tissue (Figure 1, B). Under general anesthesia, bronchoscopic dilation, using Algon plasma coagulation and debridement, was performed and repeated at 5 and 11 months postoperatively.

The patient was intubated for respiratory failure at 12 months, and the orifices of the right middle and lower lobe bronchi were almost occluded with granulation tissue (Figure 1,C). Debridement of the bronchial orifice of the

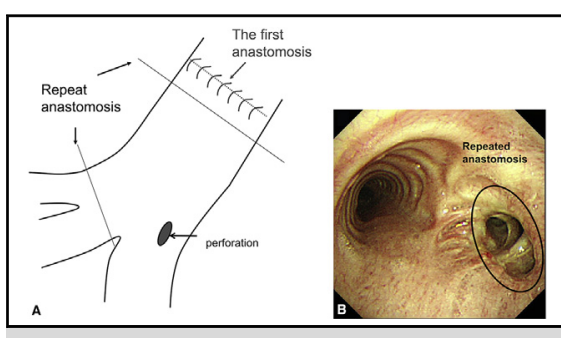

A, First anastomosis, perforation, and the repeat anastomosis. B, Satisfactory healing.

Central Message

An emergency completion pneumonectomy was performed for a bronchopleural fistula after a sleeve lobectomy. Our auto-transplantation technique enabled us to spare the lower lobe.

See Commentary on page e125.

right middle lobe resulted in a bronchopleural fistula (Figure 1,D). After obtaining the patient's consent, we proceeded with a reoperative thoracotomy.

During the reoperative thoracotomy, the intercostal muscle flap was noted to firmly adhere to the airway. Intrapericardial pneumonectomy was performed with the pulmonary vessels clamped. The incised bronchial wall was diffusely thickened. The excised lung was placed on ice slush, and an ex vivo right middle lobectomy was performed because of difficult dissection of the interlobar pulmonary artery (Figure 2, A). Thereafter, the lower lobe was perfused by ET-Kyoto solution at $4^{\circ} \mathrm{C}$. The bronchial, venous, and arterial anastomoses were performed with 4-0 polydioxanone, 6-0 polypropylene, and 6-0 polypropylene stitches, respectively. The autologous pericardial roll was interposed between the superior pulmonary vein and the venous stump of the right lower lobe graft. After the pleural space was irrigated with several liters of normal saline, the pericardial fat pad was sutured to the bronchial anastomosis. The cold ischemic time was 215 minutes, and the total operative time was 8 hours and 18 minutes (Video 2). The patient was then placed on 1 week of cefazolin. He has returned to normal life without recurrence of an anastomotic stenosis (Figure 2, B) for 3 months. 


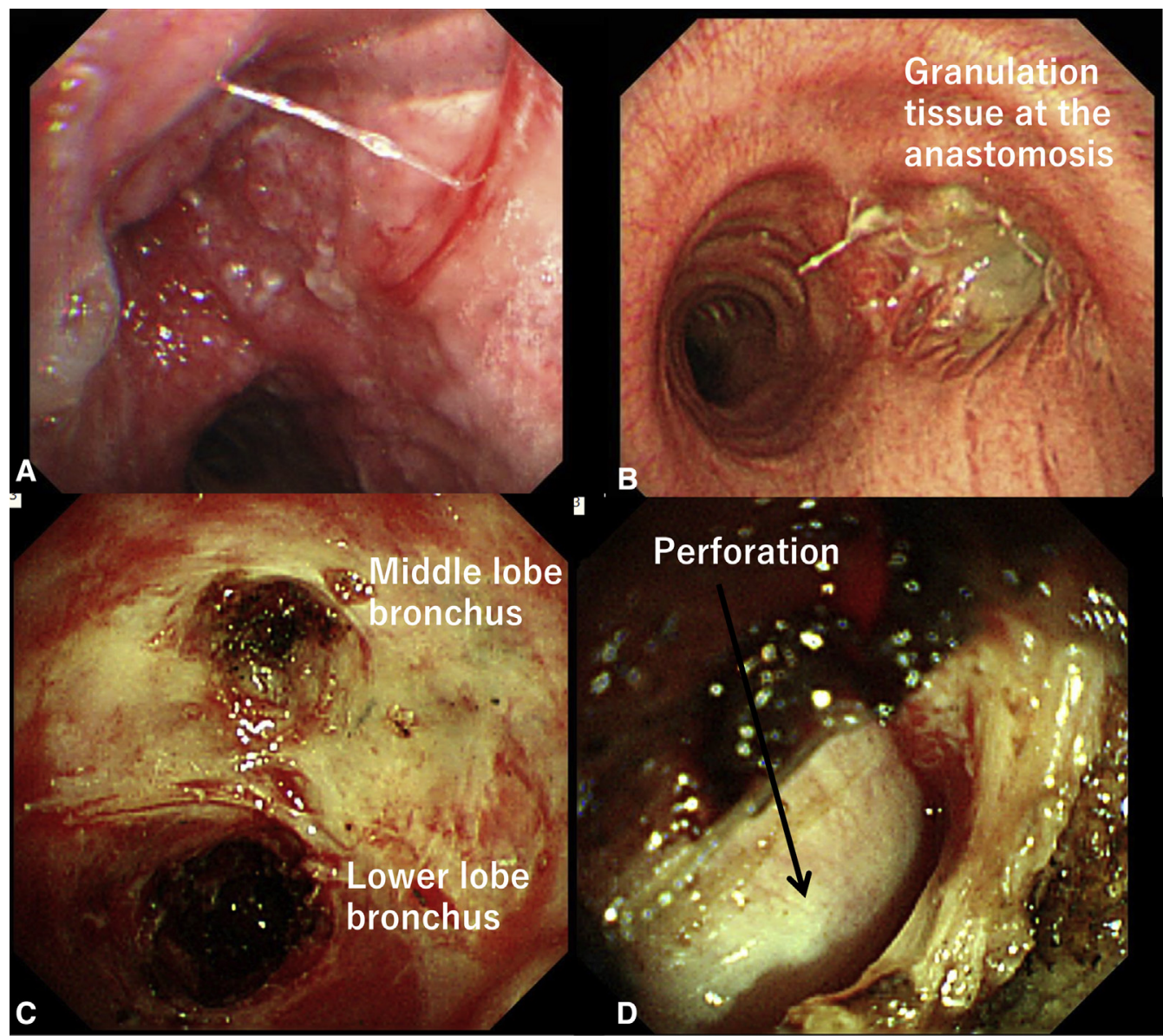

FIGURE 1. The tumor extended into the orifice of right upper lobe (A). The bronchial anastomosis was almost occluded with benign granulation tissue at 2 months (B). The orifices of the right middle and lower lobe bronchi were almost occluded with granulation tissue at 12 months (C). Bronchopleural fistula (D).

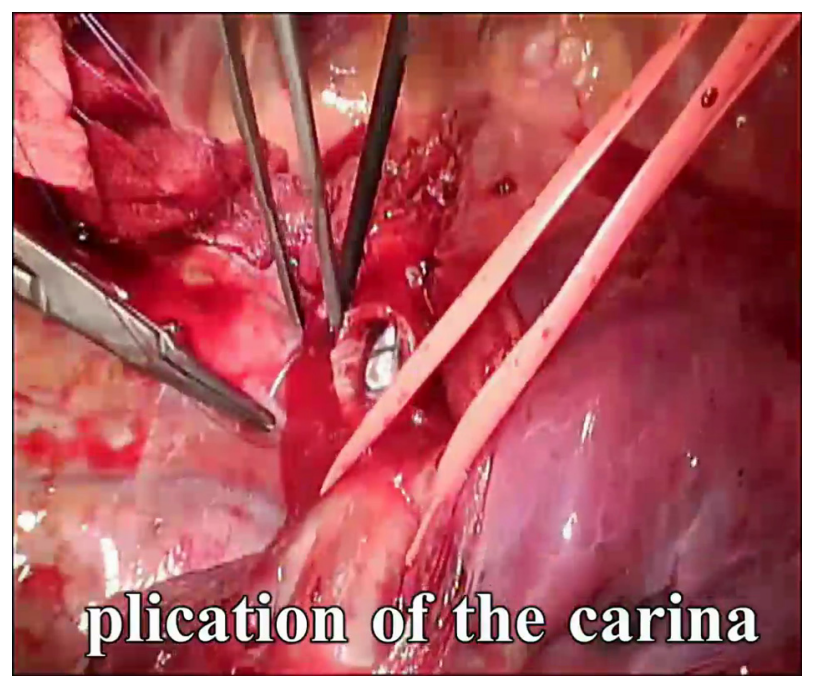

VIDEO 1. Right upper sleeve lobectomy and plication of the carina. Video available at: https://www.jtcvs.org/article/S0022-5223(19)31032-3/fulltext.

\section{DISCUSSION}

A lung auto-transplantation technique can be adopted in select patients with centrally located and advanced non-small cell lung cancer ${ }^{2}$ or benign disease. ${ }^{3}$ In this patient, to be weaned from mechanical ventilation and to minimize pleural contamination, emergency completion pneumonectomy was a required and acceptable management strategy for a bronchopleural fistula complicating bronchoscopic dilations, whereas preserving pulmonary tissue was preferred for postoperative long-term pulmonary function, considering the patient's age.

\section{CONCLUSIONS}

One alternative strategy would be the placement of a Dumon stent during a second or third stenosis. Given that no ready-made stents of appropriate shape and size were available, a 3-dimensional printed model may guide a tailor-made bronchial stent. ${ }^{4}$ Another alternative may be early reoperation (completion pneumonectomy vs resection 


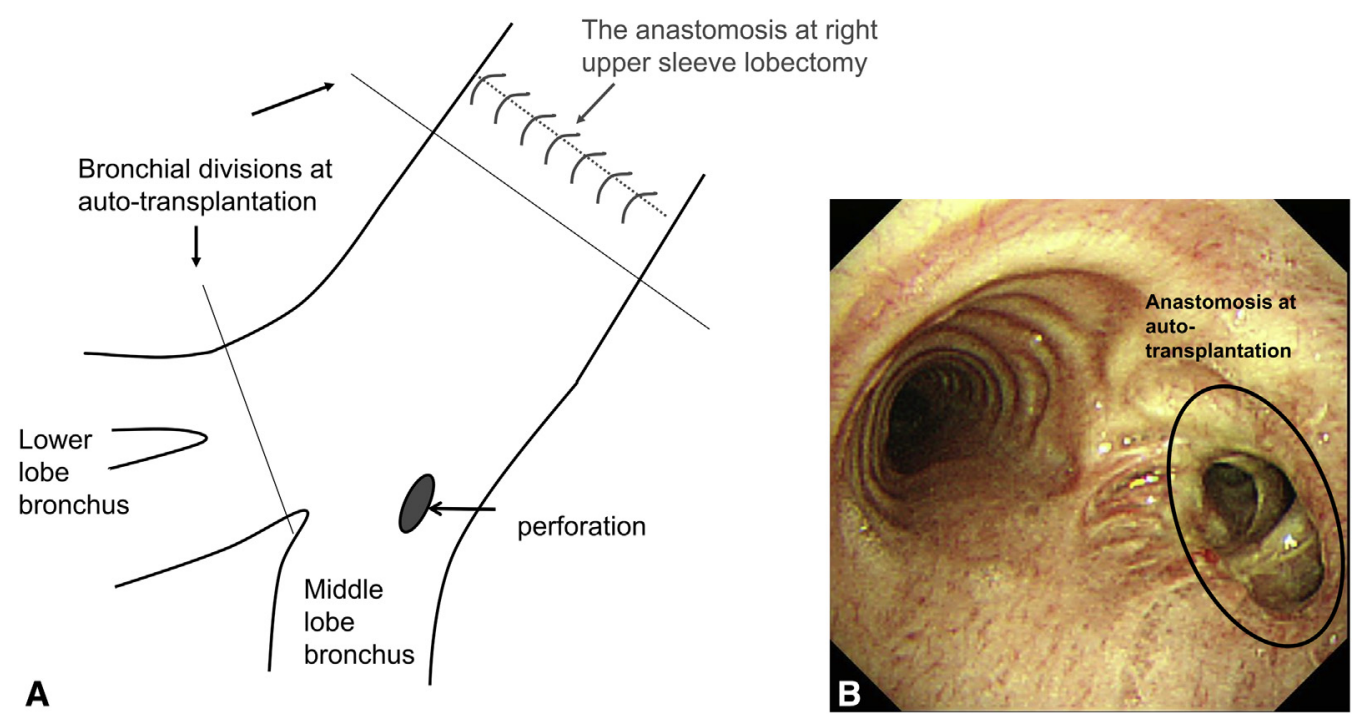

FIGURE 2. The relationship among the first bronchial anastomosis, the bronchopleural fistula, and the divisions of the bronchus at the auto-transplantation (A). The anastomosis after auto-transplantation (B).

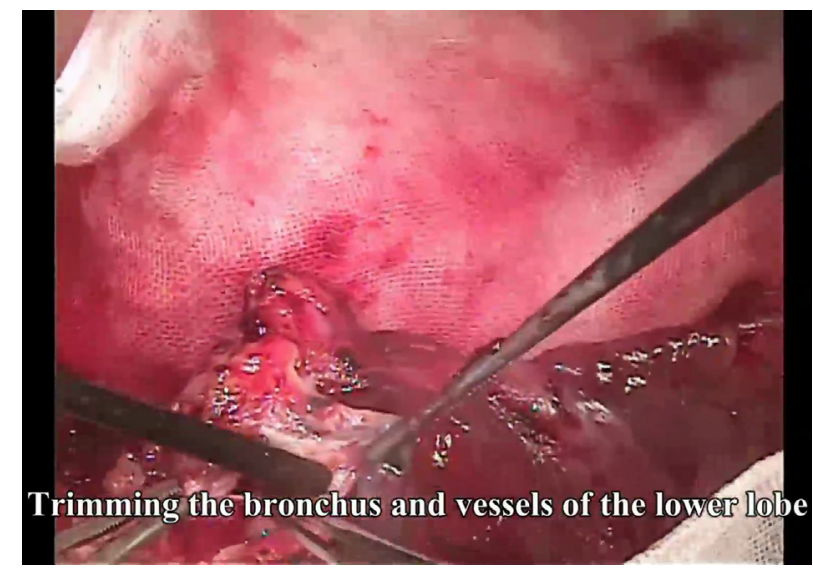

VIDEO 2. Completion pneumonectomy and auto-transplantation of right lower lobe. Video available at: https://www.jtcvs.org/article/S0022-5223(19) 31032-3/fulltext. of the anastomotic stenosis). However, no data are available regarding the outcomes of repeat bronchial anastomosis after sleeve lobectomy, and we were uncertain if resection of the anastomotic stenosis would be associated with the absence of future stenosis.

\section{References}

1. Van Schil PE, Brutel de la Rivière A, Knaepen PJ, van Swieten HA Defauw JJ, van den Bosch JM. Completion pneumonectomy after bronchial sleeve resection: incidence, indications, and results. Ann Thorac Surg. 1992; 53:1042-5.

2. Yamashita T, Hamaji M, Nakanobo R, Aoyama A, Chen-Yoshikawa TF, Sonobe M, et al. Ex-vivo sleeve lobectomy and auto-transplantation after chemoradiation. Ann Thorac Surg. 2019;107:e341-3.

3. Chen F, Takahagi A, Sakamoto K, Date H. Lung autotransplantation technique for postpneumonectomy-like syndrome. J Thorac Cardiovasc Surg. 2015;150: e45-7.

4. Guibert N, Moreno B, Plat G, Didier A, Mazieres J, Hermant C. Stenting of complex malignant central-airway obstruction guided by a three-dimensional printed model of the airways. Ann Thorac Surg. 2017;103:e357-9. 